\title{
Improved drug loading and antibacterial activity of minocycline-loaded PLGA nanoparticles prepared by solid/oil/water ion pairing method
}

This article was published in the following Dove Press journal:

International Journal of Nanomedicine

9 January 2012

Number of times this article has been viewed

\author{
Tahereh Sadat \\ Jafarzadeh Kashi' \\ Solmaz Eskandarion ${ }^{1,2}$ \\ Mehdi Esfandyari-Manesh ${ }^{3,4}$ \\ Seyyed Mahmoud \\ Amin Marashi ${ }^{5}$ \\ Nasrin Samadi ${ }^{6}$ \\ Seyyed Mostafa Fatemi ${ }^{1,7}$ \\ Fatemeh Atyabi ${ }^{2,3}$ \\ Saeed Eshraghi ${ }^{8}$ \\ Rassoul Dinarvand ${ }^{2,3}$ \\ 'Dental Materials Department, Faculty \\ of Dentistry, ${ }^{2}$ Department of \\ Pharmaceutics, ${ }^{3}$ Nanotechnology \\ Research Center, Faculty of \\ Pharmacy, Tehran University of \\ Medical Sciences, Tehran, \\ ${ }^{4}$ Department of Chemistry, Amirkabir \\ University of Technology, Tehran, \\ ${ }^{5}$ Department of Microbiology and \\ Immunology, Faculty of Medicine, \\ Babol University of Medical Sciences, \\ Babol, 'Drug and Food Control \\ Department, Faculty of Pharmacy, \\ ${ }^{7}$ Research Center of Science and \\ Technology in Medicine, ${ }^{8}$ Department \\ of Microbiology, Tehran University \\ of Medical Sciences, Tehran, Iran
}

Correspondence: Rassoul Dinarvand Faculty of Pharmacy, Tehran University of Medical Sciences, Tehran PO Box

|4|55-645I, Iran

Tel +98 2I 66959095

Fax +98 21 66959096

Email dinarvand@tums.ac.ir
Background: Low drug entrapment efficiency of hydrophilic drugs into poly(lactic-co-glycolic acid) (PLGA) nanoparticles is a major drawback. The objective of this work was to investigate different methods of producing PLGA nanoparticles containing minocycline, a drug suitable for periodontal infections.

Methods: Different methods, such as single and double solvent evaporation emulsion, ion pairing, and nanoprecipitation were used to prepare both PLGA and PEGylated PLGA nanoparticles. The resulting nanoparticles were analyzed for their morphology, particle size and size distribution, drug loading and entrapment efficiency, thermal properties, and antibacterial activity.

Results: The nanoparticles prepared in this study were spherical, with an average particle size of 85-424 nm. The entrapment efficiency of the nanoparticles prepared using different methods was as follows: solid/oil/water ion pairing $(29.9 \%)>$ oil/oil $(5.5 \%)>$ water/oil/water $(4.7 \%)>$ modified oil/water $(4.1 \%)>$ nano precipitation $(0.8 \%)$. Addition of dextran sulfate as an ion pairing agent, acting as an ionic spacer between PEGylated PLGA and minocycline, decreased the water solubility of minocycline, hence increasing the drug entrapment efficiency. Entrapment efficiency was also increased when low molecular weight PLGA and high molecular weight dextran sulfate was used. Drug release studies performed in phosphate buffer at pH 7.4 indicated slow release of minocycline from 3 days to several weeks. On antibacterial analysis, the minimum inhibitory concentration and minimum bactericidal concentration of nanoparticles was at least two times lower than that of the free drug.

Conclusion: Novel minocycline-PEGylated PLGA nanoparticles prepared by the ion pairing method had the best drug loading and entrapment efficiency compared with other prepared nanoparticles. They also showed higher in vitro antibacterial activity than the free drug.

Keywords: nanoparticle, PEGylation, PLGA, ion pairing, minocycline, antibacterial

\section{Introduction}

Many biodegradable polymers such as chitosan, gelatin, poly(lactic-co-glycolic acid) (PLGA), polymethylmethacrylate, polycaprolactone, and poly(lactic acid) are used for the preparation of microparticles and nanoparticles. ${ }^{1-5}$ PLGA is one of the most biocompatible and biodegradable polymers, and it has been widely studied for preparing drug-loaded nanoparticles. ${ }^{6,7}$ Several methods, such as phase separation or coacervation, emulsification diffusion, spray-drying, and emulsion-solvent evaporation techniques have been used to prepare PLGA nanoparticles. ${ }^{8-11}$ Using emulsion solvent evaporation methods, various drug molecules have been encapsulated into PLGA nanoparticles. ${ }^{12,13}$ For preparation of nanoparticles, the choice of a particular method primarily depends on the hydrophilicity/hydrophobicity of the drug molecule and 
stability considerations. The pattern of drug release from particles depends on some of their characteristics, including size, size distribution, entrapment efficiency, and drug loading. ${ }^{14}$ These characteristics are influenced by some of the preparation parameters, such as power and duration of energy applied, organic and aqueous phase volume, polymer and drug concentration, polymer molecular weight, and solvent volume. Each of these parameters influences the size and/or the drug loading of the nanoparticles.

In the field of oral diseases, polymeric-based drug delivery systems, such as fibers, strips, or microparticles, have been used for local drug delivery in dentistry to provide adequate drug concentrations directly at the site of action. These systems are usually inserted into the periodontal pocket or injected in periodontal tissues to both enhance the therapeutic effects of drugs and reduce the side effects of drugs related to their systemic use. Local delivery systems have been suggested as a novel concept for treatment of periodontal diseases, especially in cases that are recurrent and chronic. Several specialized local delivery systems have been designed for controlled release of antibiotics in periodontal tissues. ${ }^{15,16}$ The complexity of access to periodontal tissues makes all of these systems only partially successful. ${ }^{17}$ There are a few studies about preparation of antibacterial nanoparticles for periodontal therapy. ${ }^{18,19}$

Nanoparticles provide several advantages. For example, because of their small size, they penetrate areas (extracellular and intracellular areas) that may be inaccessible to other delivery systems, such as bacterial cells, alveolar bone trabeculae, and from the gingival sulcus inward to the underlying connective tissue and to the periodontal pocket areas below the gum line. ${ }^{17,19,20}$ Nanoparticles protect a drug against in vivo degradation and reduce side effects. They also have more favorable drug pharmacokinetics. ${ }^{21}$ Further, compared with microparticles, nanoparticles have better stability in biological fluids.

Accordingly, nanoparticles can provide a potential periodontal carrier system for the delivery of antibiotics to periodontal tissues. These systems reduce the dosage and frequency of antibiotic usage and further provide an adequate supply of antibiotics over an extended period of time. Different properties of nanoparticles, such as particle size, entrapment efficiency, minimum inhibitory concentration (MIC), minimum bactericidal concentrations (MBC), and drug release influence the clinical outcome of drug therapy via the following mechanisms:

- Smaller particle size facilitates the penetration of nanoparticles and enhances their antibacterial properties

- Higher entrapment efficiency of nanoparticles increases the drug content at the site of action
- Lower MIC and MBC achieved with nanoparticles indicates that better antibacterial activity is achieved with a smaller amount of drug

- In periodontal treatment, a higher concentration of antibiotic at initial times and thereafter a constant release of antibiotic with lower concentration is required, which is achieved with nanoparticles.

Minocycline has a broader spectrum of activity than other members of the tetracycline group of antibiotics. It is a longacting and bacteriostatic antibiotic. Generally it has serum levels higher than those of simple tetracyclines because of its long half-life. Minocycline is used primarily to treat acne and other similar skin diseases, but in accordance with the broader spectrum of activity of minocycline, it also acts against periodontal pathogens. Minocycline-loaded microcapsules have been investigated in periodontal treatments. ${ }^{22-24}$ It has been effectively used for treatment of periodontitis and related infections in periodontal diseases. ${ }^{25-27}$ The major advantage of minocycline is its anticollagenase properties and ability to reduce soft tissue destruction and bone resorption which is very important in the treatment of periodontal disease. ${ }^{19}$ In addition, minocycline is a good candidate for local antibiotic delivery. ${ }^{28,29}$ In this study, minocycline was chosen to be incorporated into PLGA nanoparticles. Due to the high hydrophilicity of minocycline and its rapid partitioning to the aqueous phase, preparation of minocycline PLGA nanoparticles remains a real challenge.

Development of new methods for the delivery of hydrophilic drugs is emerging as an important research field in pharmaceutics. ${ }^{30,31}$ In contrast with lipophilic drugs, there are some problems with encapsulation of hydrophilic agents. ${ }^{32,33}$ The commonly utilized methods for preparing hydrophilic drugs in nanoparticles suffer from low drug loading because during preparation the drug rapidly diffuses to the external aqueous phase. ${ }^{34}$ However, another problem with hydrophilic drugs is that the drug particles usually encapsulated in the form of small clusters on the surface or within the polymer matrix just below the surface of the particles, resulting in a high initial burst release. ${ }^{35}$

In this study, we used several preparation strategies to improve the encapsulation efficiency and loading of minocycline as a hydrophilic drug. Water/oil/water and solid/oil/ water emulsification were used for the hydrochloride salt form of minocycline. The oil/oil, oil/water emulsification, and nanoprecipitation methods were used for the non-salt form of minocycline. We made some modifications to the preparation methods, such as adding lecithin as an amphiphilic compound to the water phase and/or organic 
phase, or using PEGylated PLGA. ${ }^{36}$ PEG can be used as a promising material in biomedical applications, because of its good hydrophilicity, low toxicity, excellent biocompatibility, and biodegradability. ${ }^{37}$ Both the solid/oil/water and ion pairing techniques were combined in one method to encapsulate hydrophilic drugs. We hypothesized that use of PEGylated PLGA (with different molecular weights) as an amphiphilic copolymer and dextran sulfate (with different molecular weights) as an ion pairing agent could result in a better encapsulation yield of cationic molecules in nanoparticles. Dextran sulfate was used to reduce drug solubility by coacervating molecules that diffuse slowly to the external phase and allow encapsulation of the coacervate on the polymeric precipitate. Dextran sulfate is a polyanionic derivative of dextran (a polymer of anhydroglucose) and has been utilized in various pharmaceutical formulations..$^{38,39}$ Finally, nanoparticles were characterized and compared for their size, morphology, and especially drug loading, drug entrapment efficiency, and in vitro drug release profile. In addition, the antibacterial effect of nanoparticles against standard Aggregatibacter actinomycetemcomitans, the most important pathogen in periodontal infections, was investigated in vitro. ${ }^{40}$

\section{Materials and methods Materials}

PLGA (Resomer 502H and 504H, with a lactic to glycolic acid ratio of 50:50) was purchased from Boehringer Ingelheim (Ingelheim, Germany). Polyvinyl alcohol (molecular weight 30,000-70,000), dextran sulfate sodium salt (molecular weight 6000 and 500,000 Da), bifunctional $\mathrm{NH}_{2}-\mathrm{PEG}_{-} \mathrm{NH}_{2}$ (molecular weight of $3350 \mathrm{Da}$ ), sorbitan monooleate (Span 80), N-hydroxy succinimide, and dicyclohexylcarbodiimide were purchased from Sigma-Aldrich (St Louis, MO). Lecithin and high pressure liquid chromatography (HPLC) grade dimethyl formamide and tetrahydrofuran were obtained from Merck (Darmstadt, Germany). Minocycline was purchased from Kouting Chemical Co, Ltd, (Songjang, China). Deionized water was used throughout the experiment. Brain heart infusion agar (Merck) was used for microbiological tests. All other agents and solvents were analytical or reagent grade and used as received.

\section{Nanoparticle preparation $\mathrm{O} / \mathrm{W}$ emulsion technique}

Oil in water emulsification was performed according to the method developed by Esmaeili et al, with a little modification. ${ }^{41}$ Drug and polymer solution were prepared by dissolving
$150 \mathrm{mg}$ minocycline and $350 \mathrm{mg}$ of PLGA $504 \mathrm{H}$ in $20 \mathrm{~mL}$ of dichloromethane at room temperature using a magnetic stirrer (Heidolph, Germany). The organic phase was injected through a syringe equipped with a $20-\mathrm{G}$ angiocatheter into $75 \mathrm{~mL}$ of an aqueous polyvinyl alcohol solution and homogenized (Ultra-turrax, IKA, Germany) at 24,000 rpm for 5 minutes. The emulsion was then sonicated (Misonix, USA) for 2 minutes $(30 \mathrm{~W})$. The resulting nanoemulsion was maintained under a mechanical stirrer (IKA) under gentle mixing for 4 hours to evaporate off the organic solvent. After evaporation, nanoparticles were collected by centrifugation (Sigma 3K30, Germany) at 20,000 rpm for 20 minutes and washed three times with deionized water to remove nonencapsulated drug and the remaining solvent. The nanoparticle dispersion was freeze-dried at $-40^{\circ} \mathrm{C}$ for 48 hours (Christ, Alpha 2-4 LD, Germany) to obtain a fine powder.

\section{Modified O/W emulsion technique}

Phospholipid lecithin $20 \mathrm{mg}$ was added to the water phase, oil phase, and oil and water phase as an amphiphilic compound according to the method reported by Cheow and Hadinoto. ${ }^{36}$ The $\mathrm{O} / \mathrm{W}$ process was carried out according to the previous section with $100 \mathrm{mg}$ of minocycline and $400 \mathrm{mg}$ of PLGA 504H.

\section{$\mathrm{O} / \mathrm{O}$ emulsion technique}

Oil in oil emulsification was performed according to the method developed by Mahdavi et al, with a little modification. ${ }^{42}$ Drug and polymer solution was prepared by dissolving $7.5 \mathrm{mg}$ of minocycline and $37.5 \mathrm{mg}$ PLGA 504H in $3 \mathrm{~mL}$ of acetonitrile. This solution was added into $40 \mathrm{~mL}$ of viscous liquid paraffin containing $200 \mu \mathrm{L}$ Span 80 and continuously stirred, yielding a finely dispersed drug suspension. The suspension was heated to $55^{\circ} \mathrm{C}$ and stirred for 2 hours to ensure complete evaporation of acetonitrile. Nanoparticles were collected by centrifugation at 20,000 rpm for 20 minutes and washed three times with n-hexane to remove residual mineral oil and Span 80 . The nanoparticle dispersion was then freeze-dried for 48 hours.

\section{W/O/W emulsion technique}

A double emulsion process was performed according to the method developed by Dillen et al, with a little modification. ${ }^{43}$ An aqueous solution of minocycline was prepared by dissolving $25 \mathrm{mg}$ drug in $3 \mathrm{~mL}$ of deionized water (inner water phase). The solution was sonicated for 30 seconds at $20 \mathrm{~W}$ and then for 45 seconds at $35 \mathrm{~W}$. The inner water phase was injected during sonication for one minute at $20 \mathrm{~W}$ in an organic phase which consisted of $250 \mathrm{mg}$ of PLGA 504H 
dissolved in $10 \mathrm{~mL}$ of dichloromethane. The resulting W/O emulsion was dispersed in $12.5 \mathrm{~mL}$ of the first outer water phase, a $0.5 \% \mathrm{w} / \mathrm{v}$ polyvinyl alcohol solution, and then sonicated for 30 seconds at $15 \mathrm{~W}$ to obtain a multiple $\mathrm{W} / \mathrm{O} / \mathrm{W}$ emulsion. The resulting emulsion was added to the second outer phase, consisting of $60 \mathrm{~mL}$ of $0.2 \% \mathrm{w} / \mathrm{v}$ polyvinyl alcohol in order to minimize coalescence of the emulsion. The organic solvent was allowed to evaporate during 4 hours at room temperature under gentle mixing. Finally, the nanoparticles were collected by centrifugation and freeze-dried after three times washing with deionized water.

\section{S/O/W emulsion technique by ion pairing method}

The synthesis scheme for PEGylated PLGA is shown in Figure 1. PEGylated PLGA was prepared according to the method developed by Esmaeili et al with a little modification. ${ }^{8}$ Briefly, 2 g PLGA dissolved in dichloromethane was activated by dicyclohexylcarbodiimide $(207 \mathrm{mg}$ for PLGA $502 \mathrm{H}$ and $115 \mathrm{mg}$ for $504 \mathrm{H}$ ) and $\mathrm{N}$-hydroxy succinimide (414 mg for PLGA 502H and $230 \mathrm{mg}$ for 504H) at room temperature under a nitrogen atmosphere for 24 hours. The resulting mixture was filtered and precipitated by addition of ice-cold diethyl ether. The activated PLGA was dried under vacuum and then reacted with bis-amine PEG (200 mg for PLGA $504 \mathrm{H}$ and $600 \mathrm{mg}$ for $502 \mathrm{H}$ ) in $16 \mathrm{~mL}$ of dichloromethane. Stoichiometric molar ratios of $1 / 1.5$ and $1 / 1.1$ were used for PLGA 504H/bis-amine PEG and PLGA 502H/bis-amine PEG, respectively. The reaction was performed for 6 hours under nitrogen atmosphere at room temperature. The resulting mixture was precipitated by dropping it into ice-cold diethyl ether. The precipitated PEGylated PLGA was filtered, dialyzed, and dried. H-NMR spectra for PEGylated PLGA were obtained using the Bruker Avence ${ }^{\circledR} 500 \mathrm{MHz}$, in $\mathrm{CDCL}_{3}$. (Figure 2). The conjugation percentage of terminal carboxylic acid of PLGA with bis-amine PEG was $100 \%$ (H-chemical shift $-\mathrm{CH},-\mathrm{CH}_{2}$, and $-\mathrm{CH}_{3}$ of PLGA and $-\mathrm{CH}_{2}$ of $\mathrm{PEG}$ are $5.2,4.8,1.6$, and $3.7 \mathrm{~cm}^{-1}$, respectively).

The method used for preparation of PEGylated PLGA nanoparticles was a combination of $\mathrm{S} / \mathrm{O} / \mathrm{W}$ and the ion pairing technique. We prepared four nanoparticle formulations using two kinds of PLGA $(502 \mathrm{H}$ and 504H) and dextran sulfate with two molecular weights (6000 and $500,000)$. A $0.7 \mathrm{~mL}$ aqueous solution of minocycline $\mathrm{HCl}$ was injected into $10 \mathrm{~mL}$ of acetone solution containing $200 \mathrm{mg}$ PEGylated PLGA during sonication (40 W) for 60 seconds. A $0.3 \mathrm{~mL}$ aqueous solution containing $24 \mathrm{mg}$ dextran sulfate was added and sonicated for 30 seconds. The resulting solid in oil phase was added to $60 \mathrm{~mL}$ of continuous phase containing $0.5 \%$ polyvinyl alcohol as surfactant under homogenation (24,000 rpm for 5 minutes). The resulting nanoemulsion was maintained under gentle mixing for 3 hours. Consequently, the nanoparticles were collected by centrifugation and then freeze-dried after three times washing with deionized water.

\section{Nanoprecipitation technique}

Nanoprecipitation process was performed according to the method developed by Bilati et al, with a little modification. ${ }^{44}$ PLGA 504H $50 \mathrm{mg}$ and minocycline $20 \mathrm{mg}$ were dissolved in $2 \mathrm{~mL}$ of dimethyl sulfoxide to form the diffusing phase. This phase was then injected to $10 \mathrm{~mL}$ of ethanol as a nonsolvent under gentle mixing. The resulting nanoparticles were then centrifuged three times for cycles of 20 minutes at 20,000 rpm and washed with deionized water.

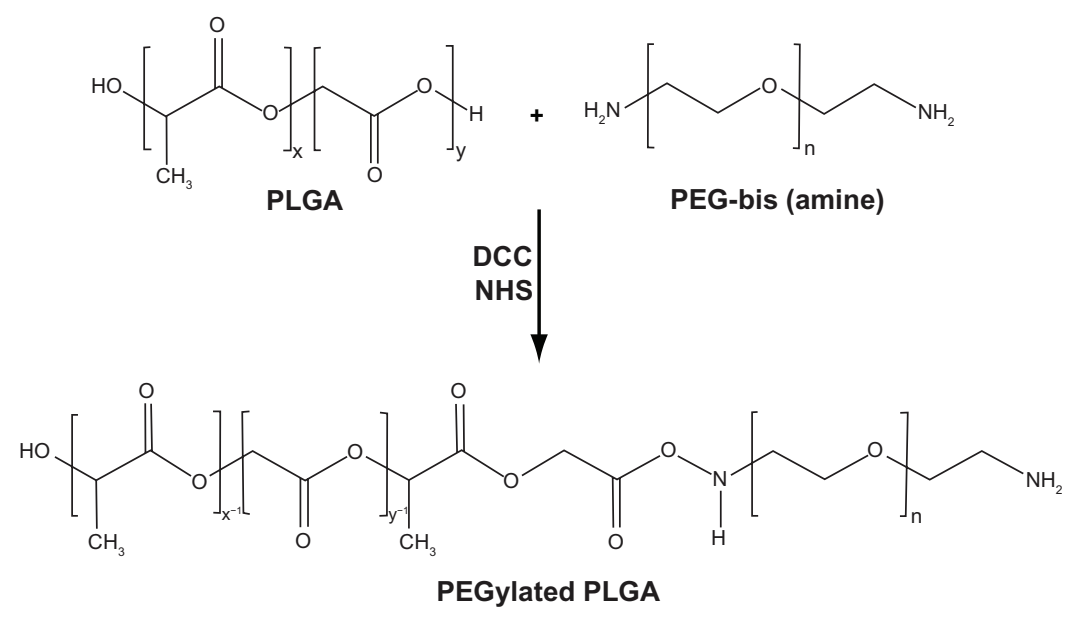

Figure I Synthesis of PEGylated-PLGA copolymer.

Abbreviations: PEG, poly(ethylene) glycol; PLGA, poly(lactic-co-glycolic acid). 


\section{Particle size and morphology characterization}

Particle size and size distribution of the nanoparticles were investigated by laser light scattering (Malvern Zetasizer ZS, Malvern, Worcestershire, UK), after suspending $5 \mathrm{mg}$ of the nanoparticles in $20 \mathrm{~mL}$ of deionized water. Three determinations were carried out for each formulation. Morphological characterization was conducted using scanning electron microscopy (30XLFEG, Philips, Eindhoven, The Netherlands). Scanning electron microscopy was employed to determine the shape and surface morphology of the nanoparticles, and the particles were coated with gold using a sputter gold coater (BAL-TEC, Switzerland) under vacuum beforehand.

\section{Differential scanning calorimetry}

Differential scanning calorimetry (DSC) of minocycline, and empty and minocycline-loaded nanoparticles were performed on a Mettler DSC 823 (Mettler Toledo, Switzerland) equipped with a Julabo Thermocryostate Model FT100Y (Julabolabortechnik GmbH, Germany). A Mettler Star software system, version 9.0× was used for data acquisition. DSC measurements were performed at a heating rate of $10^{\circ} \mathrm{C} /$ minute in the $20^{\circ} \mathrm{C}-350^{\circ} \mathrm{C}$ temperature range. The dry nanoparticles were weighed, put into an aluminum pan, and sealed carefully. During measurement, the sample cell was purged with nitrogen gas. Calibration of the instrument was performed.

\section{Determination of drug loading and entrapment efficiency}

The amount of minocycline entrapped in the nanoparticles was determined by HPLC analysis. The minocycline-loaded nanoparticles $(20 \mathrm{mg}$ ) were dissolved in $5 \mathrm{~mL}$ acetonitrile and $10 \mathrm{~mL}$ of methanol was then added to precipitate the polymer. This procedure was performed using $10 \mathrm{~mL}$ of deionized water and $10 \mathrm{~mL}$ of dimethyl formamide for the minocycline-loaded nanoparticles. The samples were passed through a $0.22 \mu \mathrm{m}$ Millipore membrane and the amount of drug was determined by HPLC analysis. The drug encapsulation efficiency was determined from the mass ratio of the encapsulated drug to the amount of drug initially added. The amount of drug loading and encapsulation efficiency were calculated using the following equations: ${ }^{42}$

Drug loading $(\%)=($ minocycline weight in sample/total weight of sample) $\times 100 \%$

Encapsulation efficiency $=($ actual $/$ theoretical minocycline loading) $\times 100 \%$

\section{In vitro minocycline release from nanoparticles}

Drug release from the nanoparticles was studied using a dialysis technique. A $20 \mathrm{mg}$ sample of nanoparticles was resuspended in $5 \mathrm{~mL}$ of phosphate buffer solution at $\mathrm{pH} 7.4$ and placed in a dialysis bag (Spectra/Por ${ }^{\circledR}$, molecular weight cutoff $2000 \mathrm{Da}$ ) sealed at both ends with clips (Spectra, Torrance, CA). The dialysis bag was soaked in $40 \mathrm{~L}$ of phosphate buffer solution $(\mathrm{pH} 7.4)$ and maintained at $37^{\circ} \mathrm{C} \pm 0.5^{\circ} \mathrm{C}$ and $100 \pm 5 \mathrm{rpm}$ shaking in a shaker (Heidolph Unimax 1010, Germany). At predetermined time intervals, individual samples were taken and the whole of the medium was replaced with $40 \mathrm{~mL}$ of fresh phosphate buffer solution. The amount of minocycline released into each medium was quantified by HPLC and compared with a standard calibration curve generated using known concentrations of minocycline.

The concentration of minocycline was analyzed using a modified USP HPLC method. HPLC analysis was performed at room temperature using a Knauer apparatus model K-1001, WellChrom (Berlin, Germany), equipped with a model PDA K-2700 ultraviolet detector (Knauer, Germany). The analytical column was Nucleodur ${ }^{\circledR} \mathrm{C} 18(25 \times 0.46 \mathrm{~cm}$ internal diameter, pore size $5 \mu \mathrm{m}$; Macherey-Nagel, Düren, Germany). The mobile phase consisted of $0.1 \mathrm{M}$ ammonium oxalate, 0.005 M edetate disodium, dimethyl formamide, and tetrahydrofuran (600:180:240:160 v/v) and adjusted with ammonium hydroxide to a $\mathrm{pH}$ of 7.2. The flow rate was fixed at $1.5 \mathrm{~mL}$ per minute and ultraviolet detection was performed at $280 \mathrm{~nm}$. The retention time of minocycline was about $7.46 \pm 0.2$ minutes. The concentration of minocycline was calculated for each sample using a calibration curve of known amounts of drug (with a linear regression coefficient of $\mathrm{R}=0.999$ ).

\section{Antibacterial properties of minocycline-loaded nanoparticles}

The antibacterial activity of the nanoparticles was compared with that of free minocycline by the well diffusion method using Aggregatibacter actinomycetocomitans (43718, American Tissue Culture Collection, Vanassus, VA). The surface of the brain heart infusion agar plates supplemented by hemin, vitamin $\mathrm{K}$, bovine serum albumin, and sheep blood were seeded by the bacterial suspension at a cell density equivalent to $0.5 \mathrm{McFarland}\left(1.5 \times 10^{8} \mathrm{CFU} / \mathrm{mL}\right)$. The antibacterial agent was sterilized by filtration using $0.22 \mu \mathrm{m}$ Millipore membranes. Wells with $8 \mathrm{~mm}$ diameters were prepared by punching a sterile cork borer onto the agar plates and removing the agar to form a well. Aliquots of $80 \mu \mathrm{L}$ of each test compound solution $(3.5 \mu \mathrm{g} / \mathrm{mL}$ 


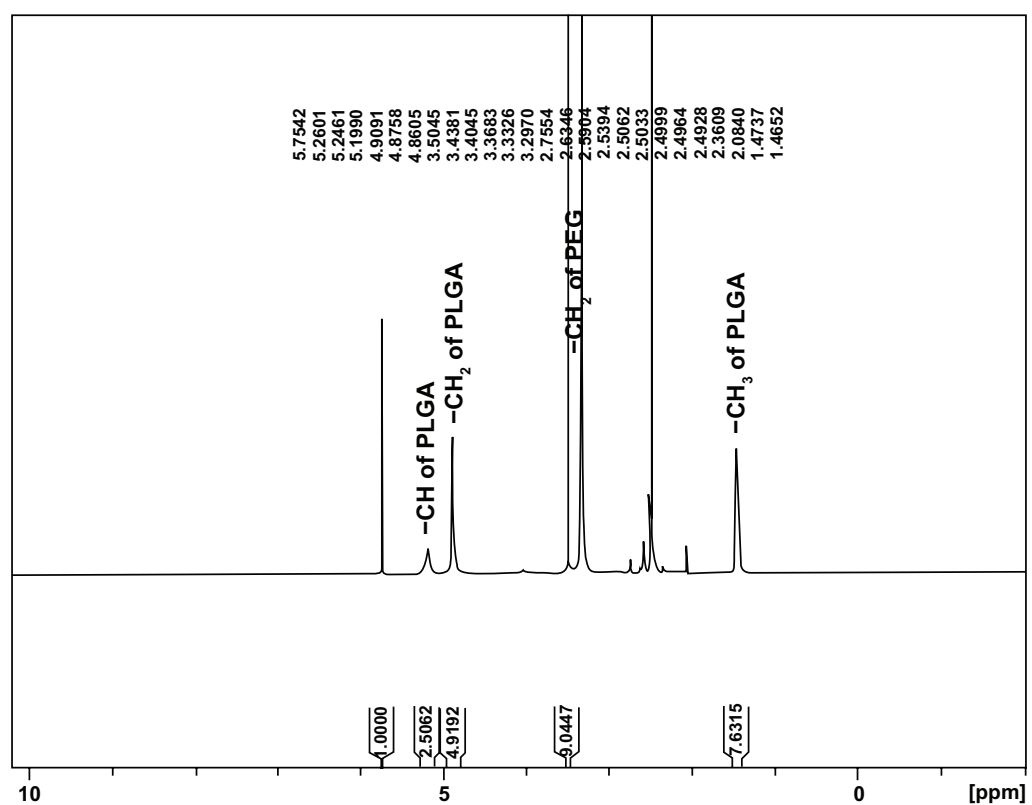

Figure $2 \mathrm{H}$-Nuclear magnetic resonance spectrum of synthesized PEGylated PLGA in $\mathrm{CDCL}_{3}$. Abbreviations: PEG, poly(ethylene) glycol; PLGA, poly(lactic-co-glycolic acid).

minocycline powder in deionized water) were delivered into the wells. After 48 hours of incubation at $37^{\circ} \mathrm{C}$, the inhibition zones around the wells were measured in millimeters using a caliper.

The MIC and MBC of the test compounds were determined using the broth macrodilution method. A stock concentration of free drug was prepared in deionized water that was further diluted in brain heart infusion broth to reach a concentration range of 0.125 to $32 \mu \mathrm{g} / \mathrm{mL}$. Based on the actual drug loading of the nanoparticles, the amount of nanoparticles in brain heart infusion broth was used to provide the equivalent concentration of minocycline similar to that of free drug. The final concentration of bacteria in the individual tubes was adjusted to about $5 \times 10^{5} \mathrm{CFU} / \mathrm{mL}$. Control tubes contained PEGylated PLGA nanoparticles without drug and with no antibacterial agent. After 48 hours of incubation at $37^{\circ} \mathrm{C}$, the test tubes were examined for possible bacterial turbidity, and the MIC of each test compound was determined as the lowest concentration that could inhibit visible bacterial growth. After MIC determination, an aliquot of $10 \mu \mathrm{L}$ from all tubes in which no visible bacterial growth was observed was seeded in brain heart infusion agar plates not supplemented with any free minocycline or minocyclineloaded nanoparticles. The plates were then incubated for 48 hours at $37^{\circ} \mathrm{C}$. The $\mathrm{MBC}$ endpoint is defined as the lowest concentration of antimicrobial agent that kills $>99.9 \%$ of the initial bacterial population where no visible growth of the bacteria was observed on the plates. ${ }^{16,41}$

\section{Statistical analysis}

Results were expressed as the mean \pm standard deviation. One-way analyses of variance were performed for evaluation of the results. $P$ values less than 0.05 were considered to be statistically significant.

\section{Results}

The basic characteristics of the minocycline-loaded nanoparticles prepared using various methods in this study are presented in Tables 1 and 2.

\section{Particle size and morphology}

All of the nanoparticles prepared from PLGA and PEGPLGA under various conditions had an acceptable size (less than $500 \mathrm{~nm}$ ) and were suitable for our final clinical purposes except for the nanoparticles prepared using the oil in oil emulsion method (OO5). The mean particle sizes (z-average) of all the samples are shown in Table 1. The range of nanoparticle size was $85-7070 \mathrm{~nm}$. It can be seen that the size of the nanoparticles was the smallest and largest when they were prepared using nanoprecipitation and the $\mathrm{O} / \mathrm{O}$ emulsion method, respectively. A typical scanning electron microphotograph of nanoparticles is shown in Figure 3. The minocycline-PLGA nanoparticles were well defined and spherical, and had a smooth surface without pores. Nanoparticles prepared by the nanoprecipitation method had the narrowest size distribution range with a polydispersity index of 0.08 (Figure 4A). Nanoparticles prepared by the 
Table I Preparation of PLGA-based nanoparticles with different methods and their particle size

\begin{tabular}{|c|c|c|c|}
\hline \multirow{3}{*}{$\begin{array}{l}\text { Sample } \\
\text { OWI }\end{array}$} & \multicolumn{2}{|c|}{ Preparation method } & \multirow{3}{*}{$\begin{array}{l}\begin{array}{l}\text { Mean } \\
\text { diameter } \\
(\mathrm{nm})\end{array} \\
193 \pm 14\end{array}$} \\
\hline & & & \\
\hline & 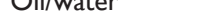 & & \\
\hline OW2 & Modified & Lecithin in water & $225 \pm 23$ \\
\hline OW3 & oil/water & Lecithin in oil & $215 \pm 16$ \\
\hline OW4 & & Lecithin in two phases & $242 \pm 21$ \\
\hline 005 & Oil/oil & & $7070 \pm 208$ \\
\hline Wow6 & Water/oil/water & & $424 \pm 17$ \\
\hline sow7 & $\begin{array}{l}\text { Solid/oil/water } \\
\text { by ion pairing }\end{array}$ & $\begin{array}{l}\text { PLGA (MW 48,000)+ } \\
\text { DS (MW 6000) }\end{array}$ & $209 \pm 19$ \\
\hline sow8 & & $\begin{array}{l}\text { PLGA (MW 48,000)+ } \\
\text { DS (MW 500,000) }\end{array}$ & $226 \pm 15$ \\
\hline sow9 & & $\begin{array}{l}\text { PLGA }(M W 12,000)+ \\
\text { DS (MW 6000) }\end{array}$ & $139 \pm 12$ \\
\hline sowio & & $\begin{array}{l}\text { PLGA }(M W 12,000)+ \\
\text { DS (MW 500,000) }\end{array}$ & $186 \pm 19$ \\
\hline NPCII & Nanoprecipitation & & $85 \pm 7$ \\
\hline
\end{tabular}

Abbreviations: DS, dextran sulfate; PLGA, poly(lactic-co-glycolic acid); MW, molecular weight.

S/O/W ion pairing method showed a somewhat good size distribution with a polydispersity index of 0.2 (Figure 4B).

\section{Drug loading and entrapment efficiency}

Table 2 displays the drug loading and entrapment efficiency for all the samples prepared using various methods. Drug loading ranged from 2.6 to $19.2 \mu \mathrm{g} / \mathrm{mg}$. The least drug loading $(0.26 \%)$ and entrapment efficiency $(0.81 \%)$ was found in nanoparticles prepared by the nanoprecipitation method. Significantly increased drug loading and entrapment efficiency was obtained by the $\mathrm{S} / \mathrm{O} / \mathrm{W}$ ion pairing method $(1.92 \%$ and $29.95 \%$ ). Inclusion of dextran sulfate into the preparations (SOW7-10) significantly lowered the percentage of free minocycline compared with those without dextran sulfate

Table 2 Drug loading and entrapment efficiency

\begin{tabular}{llc}
\hline Sample & Drug loading (\%) \pm SD & $\begin{array}{l}\text { Entrapment } \\
\text { efficiency (\%) } \pm \text { SD }\end{array}$ \\
\hline OWI & $0.41 \pm 0.02$ & $3.85 \pm 0.16$ \\
OW2 & $0.91 \pm 0.03$ & $4.14 \pm 0.03$ \\
OW3 & $0.31 \pm 0.01$ & $1.48 \pm 0.28$ \\
OW4 & $0.48 \pm 0.02$ & $2.15 \pm 0.13$ \\
OO5 & $0.98 \pm 0.04$ & $5.48 \pm 0.30$ \\
WOW6 & $0.44 \pm 0.01$ & $4.69 \pm 0.21$ \\
SOW7 & $0.46 \pm 0.015$ & $7.69 \pm 1.32$ \\
SOW8 & $0.78 \pm 0.035$ & $13.09 \pm 2.40$ \\
SOW9 & $1.32 \pm 0.12$ & $22.23 \pm 4.70$ \\
SOWI0 & $1.92 \pm 0.19$ & $29.95 \pm 2.47$ \\
NPII & $0.26 \pm 0.06$ & $0.81 \pm 0.18$ \\
\hline
\end{tabular}

Abbreviation: SD, standard deviation.

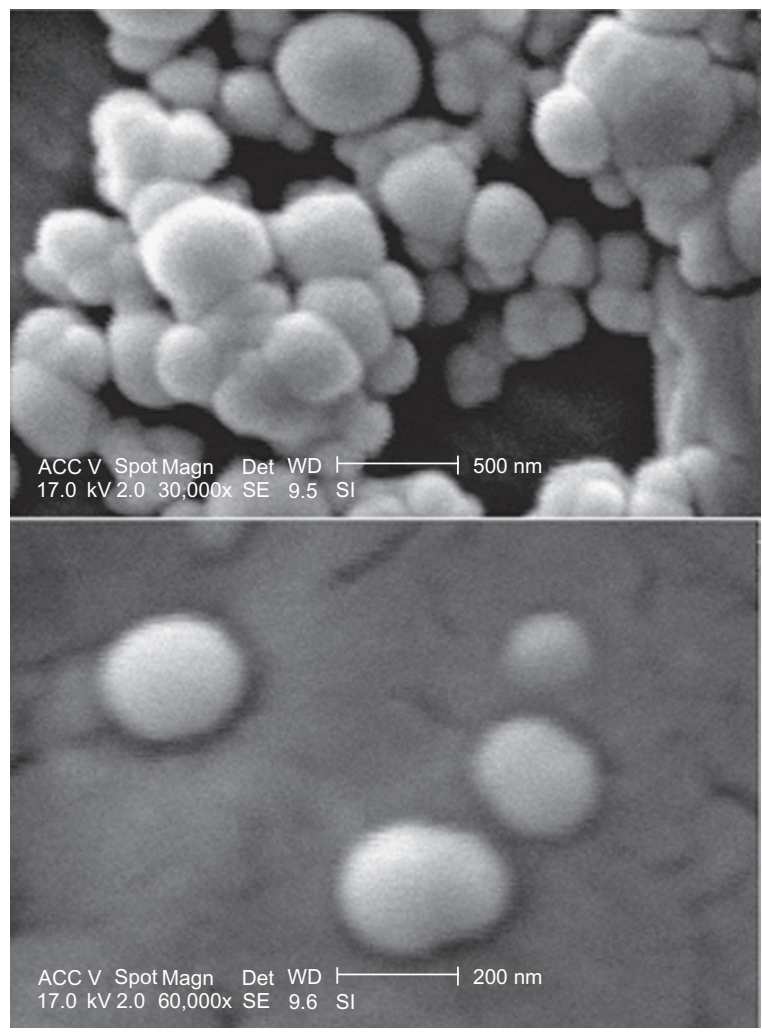

Figure 3 A typical scanning electron microphotograph of nanoparticles prepared by S/O/W ion pairing method, SOWIO (upper and lower image is presented at 30,000 and 60,000× magnification, respectively).

(WOW6) and improved drug loading compared with other formulations. Nanoparticles prepared by the $\mathrm{S} / \mathrm{O} / \mathrm{W}$ ion pairing method, with the highest entrapment efficiency, were used for other analyses.

\section{DSC analysis}

DSC thermograms of minocycline and the empty and minocycline-loaded nanoparticles were obtained to define the physical state of the drug in the nanoparticles and thermal properties of the polymer nanoparticles. Figure 5 shows the DSC thermograms for minocycline, PLGA-PEG nanoparticles, and minocycline-PLGA-PEG nanoparticles (SOW10), respectively. Pure minocycline showed an exothermic peak at $200^{\circ} \mathrm{C}$. There was no peak observed at this temperature for the nanoparticles. DSC studies did not detect any free minocycline in the nanoparticle samples. This confirmed the molecular dispersion of minocycline. After preparation the nanoparticles, minocycline could be in an amorphous phase of a molecular dispersion or in a solid solution state in the polymer matrix.

\section{In vitro drug release}

The in vitro release behavior of all nanoparticles is as cumulative percentages in Figure 6. Release over 5 days 


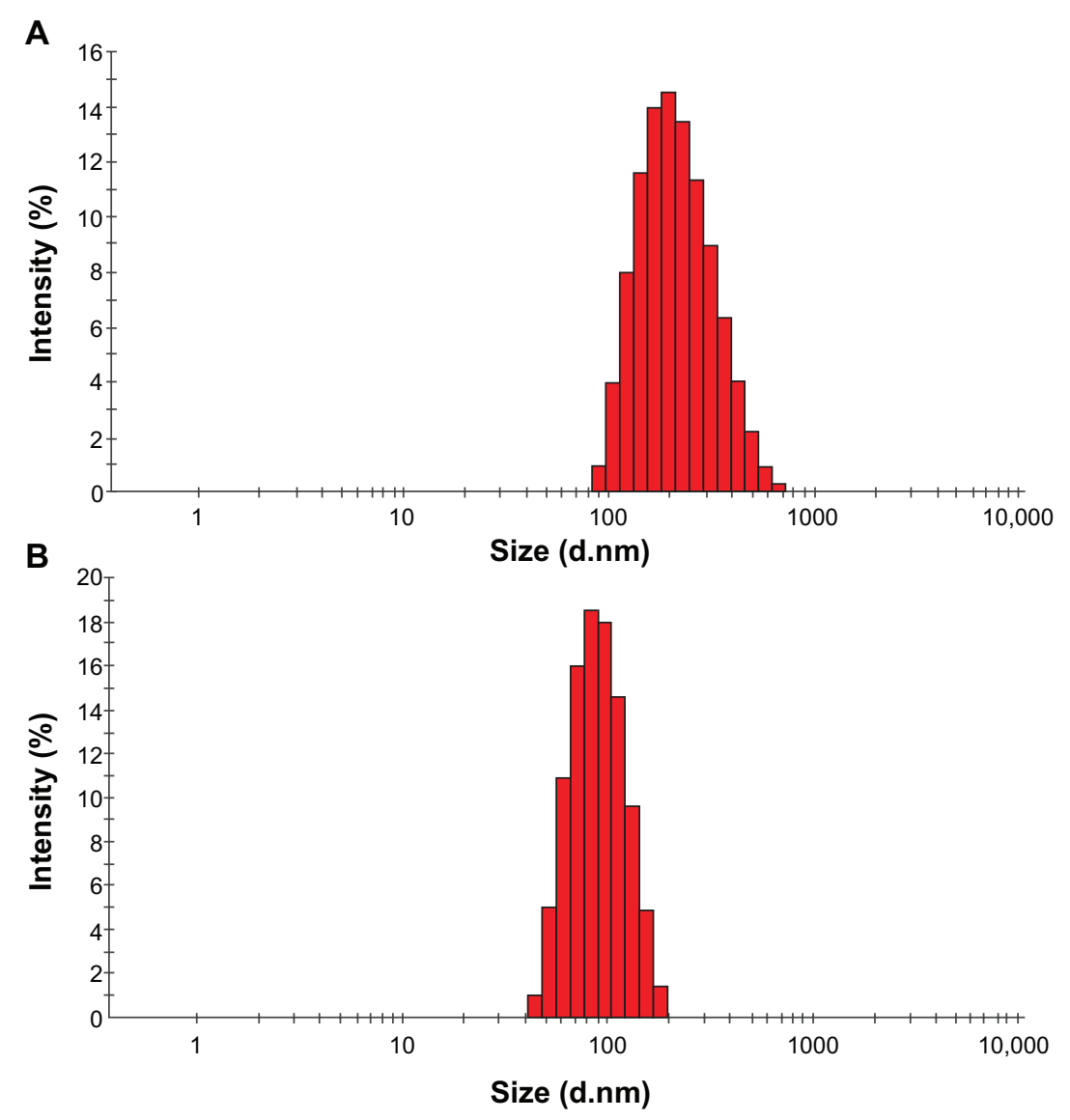

Figure 4 Particle size distributions of nanoparticles prepared by (A) S/O/W ion pairing method (SOWI0) and (B) nanoprecipitation method (NPI I).

was measured. Release profiles for nanoparticles in phosphate buffer solution ( $\mathrm{pH}$ 7.4) were affected by the preparation methods and formulations used. The initial burst release was detected for all formulations during the first 7 hours (more than 20\%) except for samples 1, 2, 5, and 6. The SOW9 formulation showed a significantly higher burst release ( $72 \%$ in 7 hours) compared with the other formulations. The rate of drug release gradually decreased after about 1-2 days and remained constant even after 5 days (except for sample 9). As shown in Figure 6, drug release from the nanoparticles prepared by $\mathrm{O} / \mathrm{O}$ was slower than from the other nanoparticles (approximately 10\% in 5 days).

\section{Antibacterial properties of minocycline nanoparticles}

The minocycline-loaded nanoparticles, free minocycline, and empty nanoparticles were tested against Aggregatibacter actinomycetemcomitans in vitro to compare their antibacterial activity. In the case of minocycline-loaded PLGA-PEG nanoparticles, the SOW10 sample had the highest entrapment efficiency. A well diffusion assay showed that the inhibition zone of minocycline-loaded nanoparticles $(9.2 \mathrm{~mm})$ was greater than that of free minocycline $(3.5 \mathrm{~mm})$ and empty PLGA nanoparticles, which did not show any inhibitory effect. The MICs of the samples are shown in Table 3. The MIC of minocycline-loaded nanoparticles $(4 \mu \mathrm{g} / \mathrm{mL})$ was two-fold less than for free minocycline $(8 \mu \mathrm{g} / \mathrm{mL})$. The MBC of minocyclineloaded nanoparticles $(8 \mu \mathrm{g} / \mathrm{mL})$ was also two-fold less than that for free minocycline $(16 \mu \mathrm{g} / \mathrm{mL})$. Therefore, it can be seen that the antibacterial activity of minocycline-loaded nanoparticles was greater than for the free drug. Empty nanoparticles diluted with brain heart infusion broth as a control did not show any antibacterial effect against the bacteria tested. Hence it can be concluded that there was no antibacterial interaction between PLGA and the tested bacteria.

\section{Discussion}

The choice of a suitable nanoparticle preparation method is dependent on the physicochemical properties of the drug to be encapsulated. Different methods have been successfully used for the entrapment of lipophilic drugs into nanoparticles. ${ }^{33,45}$ The main problem in the preparation of minocycline-loaded nanoparticles was the lack of drug loading and entrapment efficiency because minocycline is a 


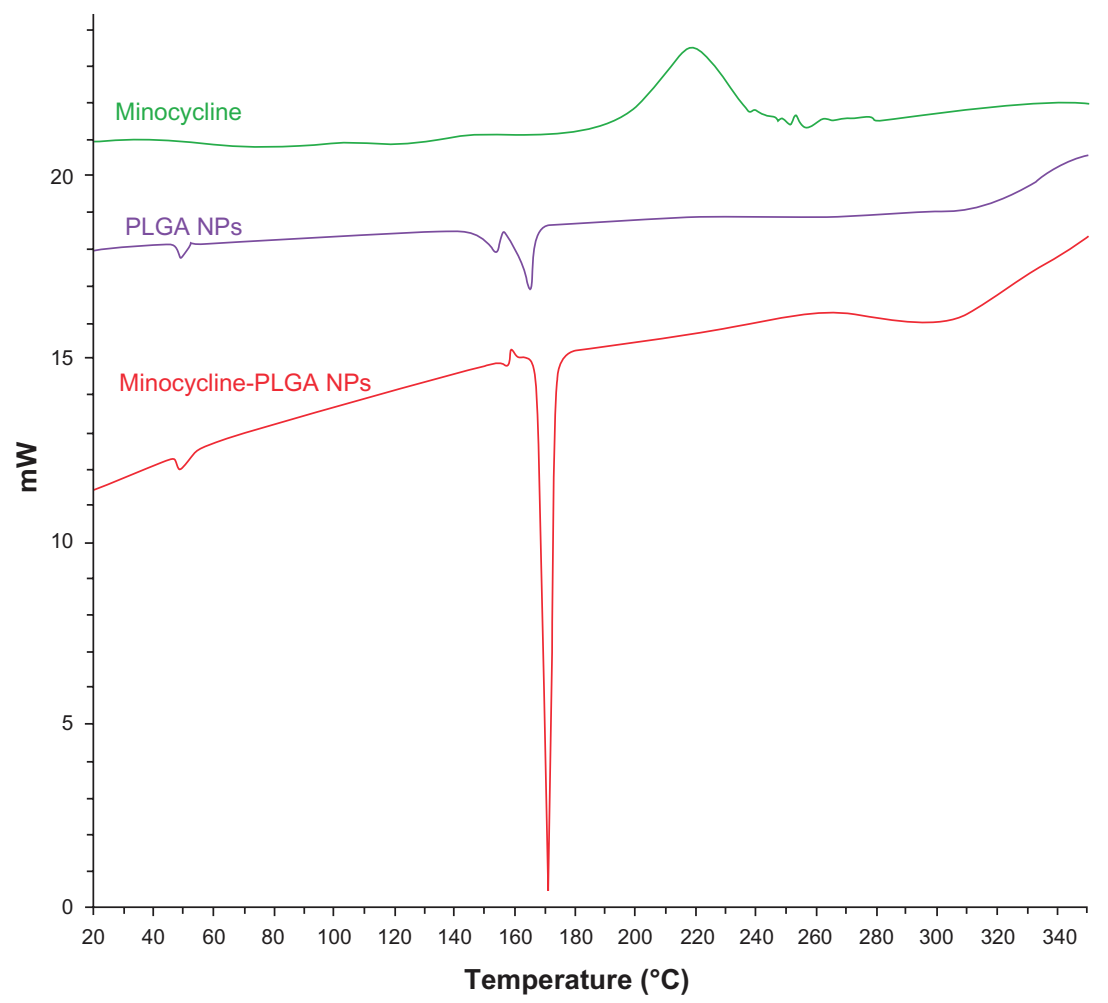

Figure 5 DSC thermograms of minocycline, PLGA-PEG, and minocycline-PLGA-PEG nanoparticles.

Abbreviations: DSC, differential scanning calorimetry; PEG, poly(ethylene) glycol; PLGA, poly(lactic-co-glycolic acid).
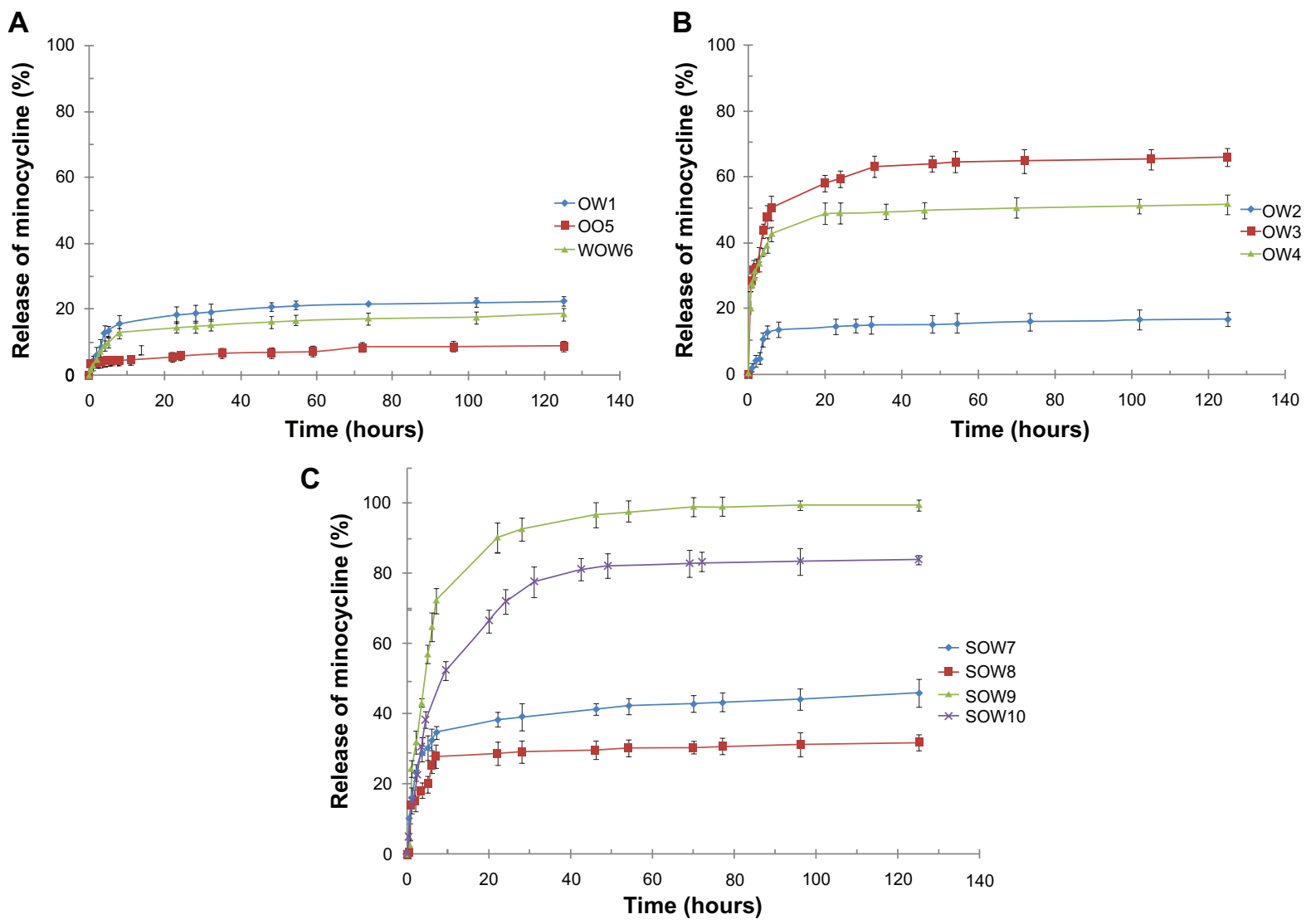

Figure 6 In vitro cumulative release of minocycline from nanoparticles (A) OWI, OO5, and WOW6; (B) modified O/W (OW2, OW3, and OW4), and (C) S/O/W ion pairing method (SOW7-10), in phosphate buffer solution $\left(\mathrm{pH} 7.4,37^{\circ} \mathrm{C}\right)$. 
Table 3 MIC and MBC of free drug and minocycline-loaded nanoparticles against Aggregatibacter actinomycetemcomitans by macrodilution method

\begin{tabular}{lll}
\hline & Free drug $(\mu \mathrm{g} / \mathrm{mL})$ & $\begin{array}{l}\text { Minocycline-loaded } \\
\text { nanoparticles }(\mu \mathrm{g} / \mathrm{mL})\end{array}$ \\
\hline MIC & 8 & 4 \\
MBC & 16 & 8 \\
\hline
\end{tabular}

Abbreviations: MIC, minimum inhibitory concentration; MBC, minimum bacterial concentration.

hydrophilic compound and there is a concern about increasing the drug loading of hydrophilic agents. ${ }^{35}$ However, in practice, preparation of nanoparticles with the desired properties (adequate entrapment efficiency and drug loading, suitable release profile, and particle size distribution) can be difficult due to the large number of factors influencing the outcome of nanoparticle preparation. In this study, several experiments were carried out to determine the best method and the formula with the highest antibiotic loading of PLGA nanoparticles.

Nanoparticles prepared by solvent diffusion methods (OW1 and WOW6) showed low entrapment efficiency and drug loading because minocycline rapidly diffused from the hydrophobic matrix into the external aqueous phase during preparation. ${ }^{46}$ Compared with the solvent diffusion method, better entrapment efficiency and drug loading were obtained by the $\mathrm{O} / \mathrm{O}$ emulsion evaporation method (OO5). This was contributed to by the liquid paraffin used as a continuation phase with this method. ${ }^{42}$ The limited solubility of minocycline and nil diffusion of first oil into liquid paraffin were advantageous to restrict minocycline leakage in comparison with other aqueous solvent diffusion methods. Polymeric particles obtained by this method had the largest particle size. An increase of particle size with the $\mathrm{O} / \mathrm{O}$ method might have been due to the high viscosity of the continuous phase which hinders the homogenous dispersion of polymer solution into the continuous phase. Particle size is key to the biological fate of nanoparticle carriers. Decreasing size improves the permeation and penetration of nanoparticle carriers. Therefore, nanoparticles should have an appropriate size to penetrate the bacterial cell wall. Inclusion of lecithin into the aqueous phase (OW2) using the O/W method led to improvement in entrapment efficiency and drug loading compared with the standard method (OW1). In this regard, adding lecithin has been shown to result in surface adsorption of amphiphilic lecithin onto nanoparticles through hydrophobic interactions. ${ }^{36}$ Minocycline interacts with the hydrophobic phospholipid tails of lecithin similar to lecithin-PLGA interactions. Incorporating lecithin onto the nanoparticle surface can enhance entrapment efficiency by trapping minocycline in the phospholipid layer. However, inclusion of lecithin in the oil phase (OW3) and both phases (oil and water) (OW4) had the reverse effect on entrapment efficiency and drug loading. Lecithin adsorption onto the nanoparticle surface caused a minor increase in particle size (about 10\%-20\%).

Nanoparticles prepared by the nanoprecipitation method were considerably smaller $(80 \pm 7 \mathrm{~nm})$ than nanoparticles prepared by the emulsion method. The size distribution of nanoparticles prepared using this method is shown in Figure 4A, where a highly uniform size distribution is observed (polydispersity index 0.08). Briefly, there are two miscible solvents when using this method. Drug and polymer dissolve in the first one as the solvent. Nanoprecipitation occurs by rapid diffusion and a precipitate of the polymer when the first polymer solution is added to the second phase as a nonsolvent. ${ }^{44}$ Precipitation involves immediate drug entrapment. Nanoparticles prepared by this method show the lowest drug loading and entrapment efficiency compared with the other methods (Table 2). Because rapid diffusion of drug-polymer solution into the second phase increased the amount of free drug in the second phase, this method was unable to retain substantial amounts of minocycline to incorporate into the polymer matrix.

High entrapment efficiency using the $\mathrm{S} / \mathrm{O} / \mathrm{W}$ ion pairing method occurred as follows. This method was a combination of $\mathrm{S} / \mathrm{O} / \mathrm{W}$ emulsion and ion pairing techniques (Figure 7). An aqueous solution of minocycline was added to an organic solution of PEGylated PLGA. Addition of aqueous dextran sulfate solution produced a minocycline-dextran sulfate precipitate (solid in oil). Dextran sulfate was used as an ion pairing agent to reduce drug solubility by coacervation. The resulting solid in the oil phase was then added to the aqueous polyvinyl alcohol solution. The organic solvent was removed by evaporation under stirring to produce nanoparticles. The electrostatic forces formed between opposite ions, cationic minocycline and anionic dextran sulfate, and cationic PEGylated PLGA and anionic dextran sulfate. Dextran sulfate as an ion pairing agent played a role as an ionic spacer between PEGylated PLGA and minocycline. If ion pairing formation is faster than polymer precipitation, the ion pairs could be trapped during particulate precipitation. In the absence of dextran sulfate (WOW6), the interactions between the terminal group of the polymer and minocycline were mostly directed by weak van der Waal's forces. According to the H-NMR results, the PEG content in low molecular weight PLGA $(502 \mathrm{H}$, molecular weight 12,000$)$ was approximately four times more than the high molecular weight PLGA $(504 \mathrm{H}$, molecular weight 48,000$)$. So a high amount of ion 


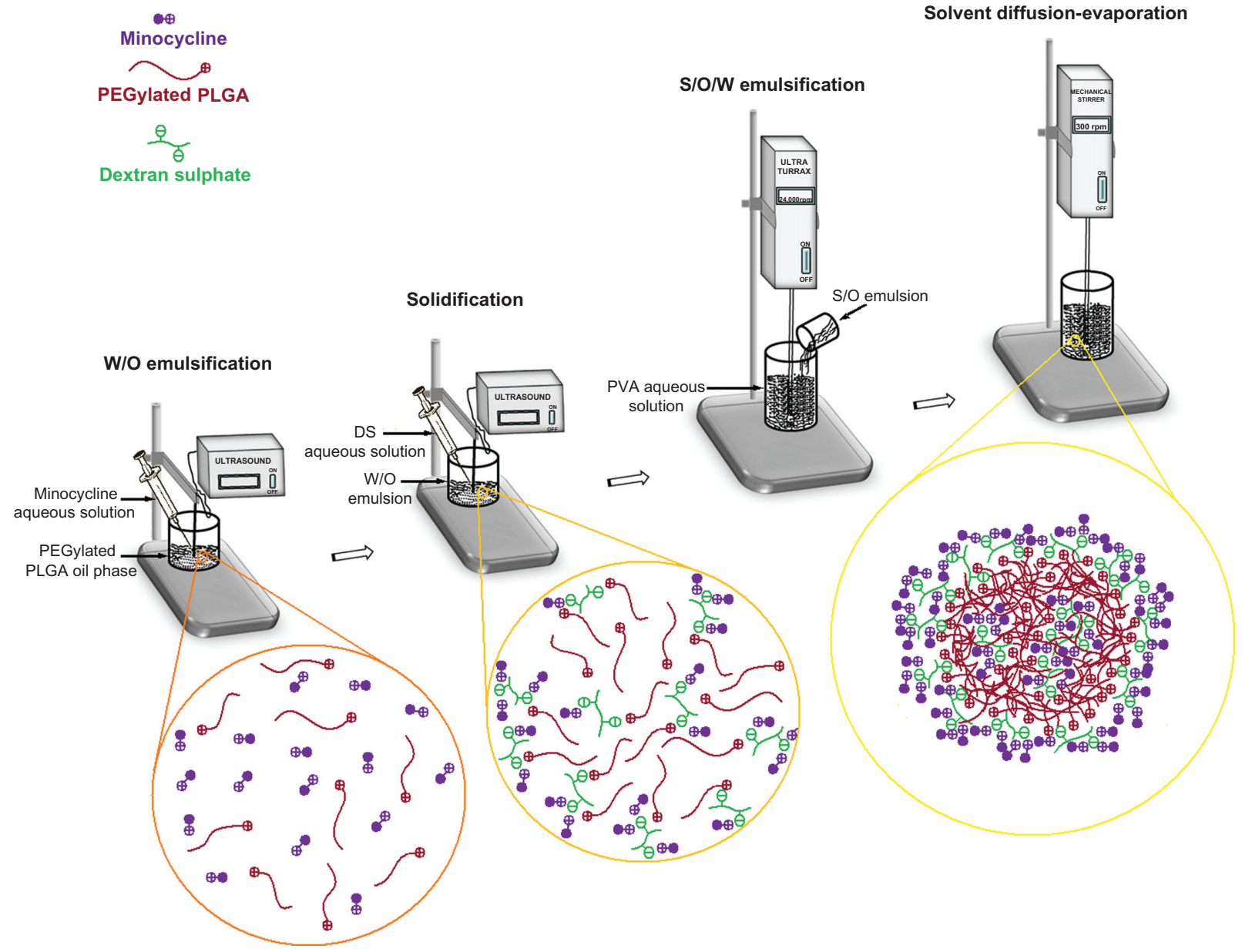

Figure 7 Scheme of combination of S/O/W emulsion and ion pairing techniques.

pairs was formed in low molecular weight PEGylated PLGA, and hence drug entrapment was increased (SOW9 and SOW10).

The significantly increased entrapment efficiency and drug loading using high molecular weight dextran sulfate $(500,000)$ indicates that the additional negative charges of dextran sulfate have further incorporated minocycline (about 2.3-2.9 times). This was due to an ion pairing mechanism which was mentioned earlier. Improved interaction between the drug and polymer and thus entrapment efficiency was obtained by increasing PEGylation and a high molecular weight of dextran sulfate.

The size of the nanoparticles prepared by different double emulsion methods was as follows: WOW6 $(424 \mathrm{~nm})>$ SOW7 $(209 \mathrm{~nm})>$ SOW9 $(139 \mathrm{~nm})$. The reduction in particle size could be largely due to the decrease in PLGA molecular weight (SOW9) and increase in amphiphilic properties of the polymer with increasing PEG content (SOW7 and 9). These polymers with higher PEG content reduce interfacial tension to facilitate nanoparticle formation, and result in a smaller particle size. ${ }^{47}$ An approximately narrow size distribution was also observed (Figure 4B) for the nanoparticles prepared by $\mathrm{S} / \mathrm{O} / \mathrm{W}$ method (polydispersity index 0.2 ).

The release kinetics of minocycline from the nanoparticles was ideal, as usually an initial burst release in the first 24 hours followed by a controlled pattern of drug release is clinically favorable. ${ }^{25,48,49}$ In most of the nanoparticles prepared in this work (OO5, WOW6, SOW7-9, NP10), we observed linear minocycline release rates after the burst effect for more than 5 days, and this profile could be ideal for periodontal disease. ${ }^{50}$ The initial burst could be ascribed to the minocycline distributed at or just beneath the surface of the nanoparticles. The later constant release is mainly due to drug diffusion and matrix erosion mechanisms. The minocycline release rate from nanoparticles in 24 hours was as follows:

- OW1 (18\%) > WOW6 (14\%) > OO5 (6\%). From the sustained drug release of $\mathrm{OO} 5$, it can be assumed that minocycline was well dispersed in the polymer matrix, which allowed regular release of minocycline with polymer degradation. The large size of the particles 
$(\mathrm{OO5}>$ WOW6 $>$ OW1) decreased the solid-liquid contact and drug diffusion through the polymeric wall.

- OW3 $(59 \%)>$ OW $4(49 \%)>$ OW1 $(18 \%)>$ OW2 (14\%). The effect of lecithin on the release rate was similar to its effect on entrapment efficiency. In sample OW2 entrapment efficiency was improved and the release rate was reduced. Conversely, in samples OW3 and OW4 entrapment efficiency was decreased and the release rate was enhanced.

- SOW9 $(91 \%)>\operatorname{SOW} 10(72 \%)$, and SOW7 $(38 \%)>$ SOW8 $(29 \%)$. Nanoparticles prepared using dextran sulfate (molecular weight 500,000 ) showed a slower release rate than dextran sulfate alone (molecular weight 6000). This may be due to a higher negative charge related to dextran sulfate 500,000 that induced better interaction with the cationic drug and which could incorporate further amounts of drug on the inside as well as the surface of the nanoparticles.

- SOW10 (72\%) > SOW 8 (29\%), and SOW9 $(91 \%)>$ SOW7 (38\%). Use of low molecular weight PLGA in SOW9 and SOW10 increased the diffusion of minocycline through the nanoparticle wall. ${ }^{51}$ Nanoparticles with the highest PEG content have more amphiphilic and hydrophilic properties. These properties enhance molecular diffusion into aqueous solution.

- SOW7 (38\%) > WOW3 (14\%). As mentioned earlier, nanoparticles prepared by the $\mathrm{S} / \mathrm{O} / \mathrm{W}$ ion pair method have more amphiphilic and hydrophilic properties and smaller particle size. These properties enhance diffusion and surface desorption in aqueous solution.

Thermal studies were used to investigate the physical state of minocycline in the nanoparticles, because this property could influence drug release from the nanoparticles. Drug may be present either as amorphous or crystalline in an amorphous or crystalline polymer. Figure 3 shows the DSC thermograms for pure minocycline, and for empty and minocycline-loaded nanoparticles. Polymer shows a glass transition temperature at $50^{\circ} \mathrm{C}$ and does not have a melting point temperature, meaning that it is an amorphous polymer. Two peaks in the temperature range of $150^{\circ} \mathrm{C}-170^{\circ} \mathrm{C}$ may be related to residence of polyvinyl alcohol. Pure minocycline showed an exothermic peak at $200^{\circ} \mathrm{C}$ related to the melting point with decomposition transition. Minocycline melting with a decomposition peak was depleted in the thermogram for the loaded nanoparticles, indicating the presence of amorphous minocycline in the nanoparticles. It may be hypothesized that crystallization of minocycline is inhibited during production of nanoparticles. Therefore, minocycline in the nanoparticles is in the amorphous phase of a molecular dispersion. The antibacterial properties of minocyclineloaded nanoparticles were determined in vitro; the antibacterial activity of the nanoparticles was remarkable and mainly attributed to the high antibacterial effect of the nanosized particles (Table 3). Encapsulation of minocycline into nanoparticles improved the antibacterial efficiency of minocycline against standard Aggregatibacter actinomycetemcomitans by two-fold. Because free drug and nanoparticles were investigated using the same concentration of minocycline, the improvement in antibacterial effect activity be due to better penetration of the nanoparticles into bacterial cells and better delivery of minocycline to its site of action. ${ }^{7}$ Nanoparticles are capable of being endocytosed by phagocytic cells and releasing drug into those cells..$^{52,53}$ The minocycline-loaded nanoparticles could be suitable for delivery of minocycline to phagocytic cells to achieve better treatment of infection compared with treatment using free minocycline. This indicates that the newly designed antibiotic-releasing nanoparticles may be appropriate for periodontal treatment.

\section{Conclusion}

Effective entrapment of drugs that are highly soluble in both aqueous and organic solvents is difficult to achieve using standard approaches, such as single and double emulsification solvent evaporation and nanoprecipitation methods. In this study we used a novel method for the preparation of minocycline-loaded nanoparticles by applying an ion pairing technique using solid/oil/water emulsification. Our results demonstrate that using PLGA-PEG-dextran sulfate for ion pairing significantly increases minocycline loading, and produces nanoparticles with the desired size, size distribution, and morphological properties. By decreasing the molecular weight of PLGA and increasing the molecular weight of dextran sulfate, the desired drug content can be obtained because of the high PEG content and low drug insolubility, respectively. PEGylated PLGA (molecular weight 12,000) and dextran sulfate (molecular weight 500,000) was the preferred choice for ion pairing because it allowed the highest drug loading and entrapment efficiency. An investigation of different preparation methods, physicochemical characterization, in vitro release testing, and antibacterial properties of the nanoparticles was carried out. Release rates varied depending on the preparation method and nanoparticle characteristics, such as amphiphilic, polymer molecular weight, particle size, and polymer composition. In vitro release indicated that after the initial burst release, controlled release 
of minocycline continued for more than 5 days; this release profile could be the ideal for periodontal disease. Nanoparticles prepared by nanoprecipitation had a good size and morphology; however, this is not an efficient method for encapsulation of highly water-soluble drugs such as minocycline (reverse of nanoparticles prepared by oil/oil method). The in vitro antibacterial results showed that the minocyclineloaded nanoparticles are remarkably more effective than the free drug against Aggregatibacter actinomycetemcomitans.

\section{Acknowledgments}

This study was funded and supported by the Tehran University of Medical Sciences (Grant 10221). The authors are grateful to the Nanotechnology Research Center of Tehran University of Medical Sciences, Tehran, Iran, for their financial support of this work. They also thank Mrs F Khosravi for her technical assistance in the experiments.

\section{Disclosure}

The authors report no conflicts of interest in this work.

\section{References}

1. Kim BK, Hwang SJ, Park JB, Park HJ. Characteristics of felodipinelocated poly (epsilon-caprolactone) microspheres. J Microencapsul. 2005;22(2):193-203.

2. Owusu-Ababio G, Rogers JA. Formulation and release kinetics of cephalexin monohydrate from biodegradable polymeric microspheres. J Microencapsul. 1996;13(2):195-205.

3. Astete CE, Sabliov CM. Synthesis and characterization of PLGA nanoparticles. J Biomater Sci Polym Ed. 2006;17(3):247-289.

4. Dinarvand R, Alimorad MM, Amanlou M, Akbari H. Preparation, characterization and in vitro drug release properties of polytrimethylene carbonate/polyadipic anhydride blend microspheres. J Appl Polym Sci. 2006;101(4):2377-2383.

5. Shokri N, Akbari Javar H, Fouladdel SH, et al. Preparation and evaluation of poly (caprolactone fumarate) nanoparticles containing doxorubicin HC1. Daru. 2011;19(1):12-22.

6. Yousefpour P, Atyabi F, Vasheghani-Farahani E, Mousavi Movahedi AA, Dinarvand R. Targeted delivery of doxorubicin-utilizing chitosan nanoparticles surface-functionalized with anti-Her2 trastuzumab. Int J Nanomedicine. 2011;6:1977-1990.

7. Dinarvand R, Sepehri N, Manoochehri H, Rouhani H, Atyabi F. Polylactide-co-glycolide nanoparticles for controlled delivery of anticancer agents. Int J Nanomedicine. 2011;6:877-895.

8. Esmaeili F, Ghahremani MH, Esmaeili B, Khoshayand MR, Atyabi F, Dinarvand R. PLGA nanoparticles of different surface properties: Preparation and evaluation of their body distribution. Int J Pharm. 2008;349(1-2):249-255.

9. Esmaeili F, Atyabi F, Dinarvand R. Preparation and characterization of estradiol-loaded PLGA nanoparticles using homogenization-solvent diffusion method. Daru. 2008;16(4):196-202.

10. $\mathrm{Mu} \mathrm{L}$, Feng SS. Fabrication, characterization and in vitro release of paclitaxel (Taxol) loaded poly (lactic-co-glycolic acid) microspheres prepared by spray drying technique with lipid/cholesterol emulsifiers. J Control Release. 2001;76(3):239-254.

11. Jang JY, Kwon BS, Lee HE, Kim DH, et al. Preparation of biodegradable PLGA nanospheres employing a fast solvent evaporation method. J Ind Eng Chem. 2007;13(6):1043-1046.
12. Jaiswal J, Gupta SK, Kreuter J. Preparation of biodegradable cyclosporine nanoparticles by high-pressure emulsification-solvent evaporation process. J Control Release. 2004;96(1):169-178.

13. Desgouilles S, Vauthier C, Bazile D, et al. The design of nanoparticles obtained by solvent evaporation: A comprehensive study. Langmuir. 2003;19(22):9504-9510.

14. Gabor F. Ketoprofen-poly(D,L-lactic-co-glycolic acid) microspheres: influence of manufacturing parameters and type of polymer on the release characteristics. J Microencapsul. 1999;16(1):1-12.

15. Esposito E, Cortesi R, Cervellati F, Menegatti E, Nastruzzi C. Biodegradable microparticles for sustained delivery of tetracycline to the periodontal pocket: formulatory and drug release studies. J Microencapsul. 1997; 14(2):175-187.

16. Schwach-Abdellaoui K, Vivien-Castioni N, Gurny R. Local delivery of antibacterial agents for the treatment of periodontal diseases. Eur J Pharm Biopharm. 2000;50(1):83-99.

17. Jain N, Jain GK, Javed SH, et al. Recent approaches for the treatment of periodontitis. Drug Discov Today. 2008;13(21-22):932-943.

18. Pragati S, Ashok S, Kuldeep S. Review: Recent advances in periodontal drug delivery systems. Int J Drug Del. 2001;3(1):1-14.

19. Pinon-Segundo E, Ganem-Quintanar A, Alonso-Perez V, QuintanarGuerrero D. Preparation and characterization of triclosan nanoparticles for periodontal treatment. Int J Pharm. 2005;294(1-2):217-232.

20. Chwalibog A, Sawosz E, Hotowy A, et al. Visualization of interaction between inorganic nanoparticles and bacteria or fungi. Int $J$ Nanomedicine. 2010;5:1085-1094.

21. Rezaei Mokarram A, Kebriaee Zadeh A, Keshavarz M, Ahmadi A, Mohtat B. Preparation and in-vitro evaluation of indomethacin nanoparticles. Daru. 2010;18(3):185-192.

22. Okuda K, Wolff L, Oliver R, et al. Minocycline slow-release formulation effect on subgingival bacteria. J Periodontol. 1992;63(2):73-79.

23. Park YJ, Lee JY, Yeom HR, et al. Injectable polysaccharide microcapsules for prolonged release of minocycline for the treatment of periodontitis. Biotechnol Lett. 2005;27(22):1761-1766.

24. Vandekerckhove BN, Quirynen M, van Steenberghe D. The use of locally delivered minocycline in the treatment of chronic periodontitis: A review of the literature. J Clin Periodontol. 1998;25(11 Pt 2):964-968.

25. Radvar M, Pourtaghi N, Kinane DF. Comparison of 3 periodontal local antibiotic therapies in persistent periodontal pockets. J Periodontol. 1996;67(9):860-865.

26. Slots J. Research, Science and Therapy Committee. Systemic antibiotics in periodontics. J Periodontol. 2004;75(11):1553-1565.

27. Heitz-Mayfield LJ. Systemic antibiotics in periodontal therapy. Aust Dent J. 2009;54 Suppl 1:96-101.

28. Jones AA, Kornman KS, Newbold DA, Manwell MA. Clinical and microbiological effects of controlled-release locally delivered minocycline in periodontitis. J Periodontol. 1994;65(11):1058-1066.

29. Timmerman MF, van der Weijden GA, van Steenbergen TJ, Mantel MS, de Graaff J, van der Velden U. Evaluation of the long-term efficacy and safety of locally-applied minocycline in adult periodontitis patients. J Clin Periodontol. 1996;23(8):707-716.

30. Fattal E, Bochot A. State of the art and perspectives for the delivery of antisense oligonucleotides and siRNA by polymeric nanocarriers. Int J Pharm. 2008;364(2):237-248.

31. Ishihara T, Mizushima T. Techniques for efficient entrapment of pharmaceuticals in biodegradable solid micro/nanoparticles. Expert Opin Drug Deliv. 2010;7(5):565-575.

32. Chorny M, Fishbein I, Danenberg HD, Golomb G. Lipophilic drug loaded nanospheres prepared by nanoprecipitation: effect of formulation variables on size, drug recovery and release kinetics. J Control Release. 2002;83(3):389-400.

33. Wischke C, Schwendeman SP. Principles of encapsulating hydrophobic drugs in PLA/PLGA microparticles. Int J Pharm. 2008;364(2): 298-327.

34. Govender T, Stolnik S, Garnett MC, Illum L, Davis SS. PLGA nanoparticles prepared by nanoprecipitation: drug loading and release studies of a water soluble drug. J Control Release. 1999;57(2):171-185. 
35. Thote AJ, Gupta RB. Formation of nanoparticles of a hydrophilic drug using supercritical carbon dioxide and microencapsulation for sustained release. Nanomedicine. 2005;1(1):85-90.

36. Cheow WS, Hadinoto K. Enhancing encapsulation efficiency of highly water-soluble antibiotic in poly(lactic-co-glycolic acid) nanoparticles: Modifications of standard nanoparticle preparation methods. Colloids Surf A Physicochem Eng Aspects. 2010;370(1-3):79-86.

37. Lu C, Zhong W. Synthesis of propargyl-terminated heterobifunctional poly(ethylene glycol). Polymers. 2010;2(4):407-417.

38. Dalwadi G, Sunderland B. An ion pairing approach to increase the loading of hydrophilic and lipophilic drugs into PEGylated PLGA nanoparticles. Eur J Pharm Biopharm. 2009;71(2):231-242.

39. Tan ML, Friedhuber AM, Dunstan DE, Choong PF, Dass CR. The performance of doxorubicin encapsulated in chitosan-dextran sulphate microparticles in an osteosarcoma model. Biomaterials. 2010;31(3): 541-551.

40. Fine DH, Markowitz K, Furgang D, et al. Aggregatibacter actinomycetemcomitans and its relationship to initiation of localized aggressive periodontitis: longitudinal cohort study of initially healthy adolescents. J Clin Microbiol. 2007;45(12):3859-3869.

41. Esmaeili F, Hosseini-Nasr M, Rad-Malekshahi M, Samadi N, Atyabi F, Dinarvand R. Preparation and antibacterial activity evaluation of rifampicin-loaded poly lactide-co-glycolide nanoparticles. Nanomedicine. 2007;3(2):161-167.

42. Mahdavi H, Mirzadeh H, Hamishehkar H, et al. The effect of process parameters on the size and morphology of poly(D,L-lactide-coglycolide) micro/nanoparticles prepared by an oil in oil emulsion/solvent evaporation technique. J Appl Polym Sci. 2010;116(1):528-534.

43. Dillen K, Vandervoort J, Van den Mooter G, Verheyden L, Ludwiga A. Factorial design, physicochemical characterisation and activity of ciprofloxacin-PLGA nanoparticles. Int J Pharm. 2004;275(1-2): 171-187.

44. Bilati U, Allemann E, Doelker E. Development of a nanoprecipitation method intended for the entrapment of hydrophilic drugs into nanoparticles. Eur J Pharm Sci. 2005;24(1):67-75.
45. Barichello JM, Morishita M, Takayama K, Nagai T. Encapsulation of hydrophilic and lipophilic drugs in PLGA nanoparticles by the nanoprecipitation method. Drug Dev Ind Pharm. 1999;25(4):471-476.

46. Yuan H, Jiang SP, Du YZ, Miao J, Zhang XG, Hu FQ. Strategic approaches for improving entrapment of hydrophilic peptide drugs by lipid nanoparticles. Colloids Surf B Biointerfaces. 2009;70(2): 248-253.

47. Riley T, Stolnik S, Heald R, et al. Physicochemical evaluation of nanoparticles assembled from poly(lactic acid)-Poly(ethylene glycol) (PLA-PEG) block copolymers as drug delivery vehicles. Langmuir. 2001;17(11):3168-3174.

48. Lindhe J, Haffajee AD, Socransky SS. Progression of periodontal disease in adult subjects in the absence of periodontal therapy. J Clin Periodontol. 1983;10(4):433-442.

49. Listgarten MA. Nature of periodontal diseases: pathogenic mechanisms. J Periodontal Res. 1987;22(3):172-178.

50. Mundargi RC, Srirangarajan S, Agnihotri SA, et al. Development and evaluation of novel biodegradable microspheres based on poly(d,1lactide-co-glycolide) and poly(epsilon-caprolactone) for controlled delivery of doxycycline in the treatment of human periodontal pocket: in vitro and in vivo studies. J Control Release. 2007;119(1):59-68.

51. Graves RA, Pamujula S, Moiseyev R, Freeman T, Bostanian LA, Mandal TK. Effect of different ratios of high and low molecular weight PLGA blend on the characteristics of pentamidine microcapsules. Int J Pharm. 2004;270(1-2):251-262.

52. Mohammadi G, Nokhodchi A, Barzegar-Jalali M, et al. Physicochemical and anti-bacterial performance characterization of clarithromycin nanoparticles as colloidal drug delivery system. Colloid Surf B Biointerfaces. 2011;88(1):39-44.

53. Page-Clisson ME, Pinto-Alphandary H, Ourevitch M, Andremont A, Couvreur P. Development of ciprofloxacin-loaded nanoparticles: physicochemical study of the drug carrier. J Control Release. 1998; 56(1-3):23-32.
International Journal of Nanomedicine

\section{Publish your work in this journal}

The International Journal of Nanomedicine is an international, peerreviewed journal focusing on the application of nanotechnology in diagnostics, therapeutics, and drug delivery systems throughout the biomedical field. This journal is indexed on PubMed Central, MedLine, CAS, SciSearch ${ }^{\circledR}$, Current Contents ${ } /$ Clinical Medicine, Journal

\section{Dovepress}

Citation Reports/Science Edition, EMBase, Scopus and the Elsevier Bibliographic databases. The manuscript management system is completely online and includes a very quick and fair peer-review system, which is all easy to use. Visit http://www.dovepress.com/ testimonials.php to read real quotes from published authors. 